\title{
DIGITALCOMMONS
}

@WAYNESTATE-

Wayne State University

Kinesiology, Health and Sport Studies

College of Education

$1-1-2014$

\section{Psychometric Support for the Ownership in Exercise and Empowerment in Exercise Scales}

E. Whitney G. Moore

Wayne State University, whitneymoore@wayne.edu

Mary D. Fry

University of Kansas

\section{Recommended Citation}

E. Whitney G. Moore \& Mary D. Fry (2014) Psychometric Support for the Ownership in Exercise and Empowerment in Exercise Scales, Measurement in Physical Education and Exercise Science, 18:2, 135-151, DOI: 10.1080/1091367X.2013.875472

Available at: http://digitalcommons.wayne.edu/coe_khs/55 
Running head: EXERCISE OWNERSHIP AND EMPOWERMENT PSYCHOMETRICS

\title{
Psychometric Support for the Ownership in Exercise and Empowerment in
}

\author{
Exercise Scales
}

\author{
E. Whitney G. Moore \\ Department of Kinesiology, Health Promotion, and Recreation, University of North Texas, Denton, \\ Texas \\ Mary D. Fry \\ Department of Health, Sport and Exercise Sciences, University of Kansas, Lawrence, Kansas
}

\begin{abstract}
This study's purpose was to examine the psychometric properties of two new scales developed to quantitatively measure participants' ownership in exercise classes and empowerment with respect to exercise. These two outcome measures will compliment Achievement Goal Perspective Theory (AGPT) grounded research to better understand participants' exercise experiences. College exercise class participants $\left(N=414 ; M_{\text {age }}=\right.$ 21.25 years; $67 \%$ female) completed the survey during the last two weeks of a semester. Measurement invariance was assessed by a two-group (i.e., male and female) confirmatory factor analysis and used Mplus' cluster option to account for the data's nested nature. Strong invariance was achieved, which provided psychometric evidence for the ownership and empowerment in exercise measures. Additional validity support was provided by the ownership and empowerment latent relationships aligning with the researchers a priori hypotheses. These results provide preliminary validity evidence for the Ownership in Exercise and Empowerment in Exercise Scales.
\end{abstract}

Keywords: exercise climate, motivation, students, measurement, factorial invariance 


\section{Psychometric Support for the Ownership in Exercise and Empowerment in Exercise}

\section{Scales}

Research employing Nicholls’ Achievement Goal Perspective Theory (AGPT; Nicholls, 1989) has consistently revealed that highly task-involving climates are associated with many positive outcomes in a variety of academic and physical activity settings (e.g., classrooms, recreational and competitive sport), whereas highly ego-involving climates have been associated with more maladaptive outcomes in both academic and physical activity settings (Nicholls, 1989; for a review see Roberts \& Treasure, 2012). Recent research has focused on the additional positive benefits that occur when a motivational climate is perceived as caring (Gano-Overway et al., 2009; Newton, Fry et al., 2007; Newton, Watson et al., 2007). The purpose of this study was to examine the psychometric properties of two newly developed quantitative measures: the Ownership in Exercise Scale (OES) and Empowerment in Exercise Scale (EES). The ability to quantitatively measure these constructs will help researchers better understand the mechanism through which individuals' perceptions of the climate in exercise settings influence their overall experiences and desire to exercise over time. This study serves as the first step in providing psychometric support for these two new measures by examining the quality of their measurement model and the cross-sectional relationships of the latent constructs with the motivational climates (i.e., concurrent validity).

AGPT was developed to systematically research how to optimize individuals' motivation within educational achievement settings. Nicholls (1989) identified two distinct climates (i.e., task-involving and ego-involving) that typically have a moderate, negative correlation (GanoOverway, Guivernau, Magyar, Waldron, \& Ewing, 2005; Newton, Duda, \& Yin, 2000; Walling, Duda, \& Chi, 1993). In a task-involving climate participants' effort and improvement are recognized, every individual plays an important role, and cooperation is fostered (Newton et al., 
2000). When participants perceive a task-involving climate to be emphasized, they have consistently reported more positive outcomes, such as significantly more enjoyment, effort, positive relationships with teammates/coaches, and increased interest in future participation (Duda \& Nicholls, 1992; Gano-Overway et al., 2005; Gano-Overway et al., 2009; Seifriz, Duda, \& Chi, 1992; Walling, Duda, \& Chi, 1993). In contrast, in an ego-involving climate individuals' ability and improvement are judged against normative standards and peer comparison, leaders employ greater use of punishment for mistakes or poor performance, and leaders consistently give more attention and praise to the few with the highest ability (Newton et al., 2000). When participants perceive these ego-involving climate components to be emphasized they also report more negative outcomes, such as decreased enjoyment, team satisfaction, sportpersonship, and self-esteem; and increased performance-related tension/worry (Duda et al., 1995; Duda \& Nicholls, 1992; Gano-Overway et al., 2005; Gano-Overway et al., 2009; Seifriz et al., 1992; Walling et al., 1993). The relationships of the task- and ego-involving climates to these outcome variables have been reported consistently across academic, sport, and exercise domains.

Another aspect of the climate, and one that has gained recent attention in exercise psychology, is participants' perceptions of the climate as caring. A caring climate has been operationally defined as “...the extent to which individuals perceive a particular setting to be interpersonally inviting, safe, supportive and capable of providing the experience of being valued and respected" (Newton, Fry et al., 2007, p. 70). Fostering a respectful, fair, safe, welcoming, and comfortable environment may enhance leaders' opportunities to understand and accept participants for who they are (Newton, Fry et al., 2007). Gano-Overway et al. (2009) found that individuals' perceptions of a caring climate had a positive effect on their pro-social behavior and empathetic abilities, which decreased their antisocial behavior, as well. Additionally, when exercise participants perceived the climate to be both highly caring and task-involving, they 
reported significantly increased effort, enjoyment, and expected future participation (Brown \& Fry, 2013; Gano-Overway et al., 2009). To date, caring climate studies have primarily been conducted with youth in sport and exercise settings.

Although currently limited, climate research in the exercise setting has become increasingly important due to the continued accelerated rise in both the United States' and international inactivity rates (Holwegner \& Weber, 2009; World Health Organization [WHO], 2013). As of 2010, physical inactivity passed obesity to become the fourth greatest mortality risk factor internationally (WHO, 2010). Despite exercise's well documented health benefits (e.g., decreased blood pressure, increased blood glucose sensitivity, and decreased heart disease), the majority of U.S. adults do not meet the minimum recommendations (i.e., 150 minutes of moderate to vigorous physical activity a week; Surgeon General, 1999; U.S. Department of Health and Human Services, 2008; WHO, 2010). Researchers have identified the following barriers to adults' regularly exercising: a negative personal view towards exercise, too much effort required to exercise, and not identifying as an active person (Auweele, Rzewnicki, \& Van Mele, 1997; Thøgersen-Ntoumani, Ntoumanis, \& Nikitaras, 2008). Unfortunately, a current trend in the United States that may only perpetuate these views among the younger generation is the decreased requirements by most states for physical education at the primary and secondary levels. Chomitz et al. (2009) suggested that the diminished K-12 physical education in the U.S. may have inadvertently passed the responsibility to develop active young adults on to colleges and universities. In essence, more graduating high school students may identify less with having an active lifestyle, and be less prepared (e.g., have less knowledge and/or experience) to be involved in exercise classes (e.g., through schools, and publicly or privately owned facilities) that would help young adults develop an active lifestyle compared to previous generations. This potential convergence of factors has increased the need to maximize positive exercise class 
experiences, because the habits developed by young adults often continue the rest of their lives (Barnekow-Bergkvist, Hedberg, Janlert, \& Jansson, 1996; Sallis \& Patrick, 1994).

\section{Ownership in Exercise}

Previous research suggests that the motivational climate influences individuals' exercise experiences (Huddleston, Fry, \& Brown, 2012; Brown, Fry, \& Little, 2013; Roberts \& Treasure, 2012). This study introduces two new outcome measures to the motivational climate and exercise literature that focus on participants' exercise experience (ownership) and ability to overcome future participation barriers (empowerment). Although ownership and empowerment have been researched in educational contexts and in qualitative studies, they have not been quantitatively assessed in the exercise context.

Ownership refers to the participants' sense of having a stake or vote (Merriam-Webster, 2009). For the purposes of this study, ownership in exercise was operationally defined as the participants' sense of having a positive influence over the quality of their own, and the group's experience. When participants have a sense of ownership in exercise, they see themselves and their peers as having an integral and influential role in the class' activity and the overall quality of the experience. When participants lack this sense of ownership, they may view the instructor more as a dictator than as a facilitator. A leader as dictator perception may result in the view that the class is the instructor's, rather than collectively the participants'. On the other hand, a leader as facilitator perception would encourage participants to take ownership of the class. For this reason, a highly caring, task-involving, low ego-involving climate is hypothesized to set the foundation for participants' ownership to thrive. This means the participants' sense of influence, responsibility, and having an important role may increase. Holding this view of ownership may partially explain participants' increased effort and enjoyment in task-involving and caring climates, because their involvement and input positively influences their own, and others' class 
experience. Thus, regardless of the exercise outcome, participants are more likely to take responsibility for it and "own the experience." Although ownership has been identified as an important applied concept in the academic domain (e.g., student-directed projects; Enghag, Gustafsson, \& Jonsson, 2009; Enghag \& Niedderer, 2008; Powell, 2005), it has yet to be considered in research in the physical domain. Therefore, one aim of this study was to begin developing a quantitative measure of ownership appropriate for use in an exercise setting.

\section{Empowerment in Exercise}

An additional aim of this study was to assess the quantitative validity of the empowerment in exercise scale. In this study, exercise empowerment is defined as the participants' increased sense of their ability to control and reach their physical fitness and health potential through continued exercise, including transference benefits from their current exercise class experience. Although a quantitative measure for empowerment in exercise did not yet exist, there had been some qualitative research on empowerment in education and sport (Blinde, Taub, \& Han, 1993; Lavoi, 2007). Lavoi’s (2007) qualitative study with collegiate athletes identifying "coach-athlete closeness" concepts, defined empowerment as "the experience of feeling personally strengthened, encouraged and inspired to take action through connection in a relationship" (Lavoi, 2007, p. 504). This framing by the athletes emphasized the facilitative relationship necessary from the activity leader to foster participants' empowerment. Through such support, empowered individuals may develop the perception that they can affect change in their own health and fitness status. Thus, empowerment is expected to occur more often when the perceived climate is positive and supportive, and participants view themselves as their own agents of change and their instructor as the facilitator.

A perception of exercise empowerment may help explain why some participants can successfully overcome obstacles on the road to achieving long-term exercise behavior change. 
Blinde, Taub, and Han (1993) found collegiate female athletes described the empowerment they developed through sports participation as resulting in "(a) bodily competence, (b) perceptions of a competent self, and (c) a proactive approach to life" (Blinde, Taub, \& Han, 1993, p. 159). Exercisers who have a high perception of exercise empowerment may express similar outcomes. These positive outcomes may explain how empowerment could assist individuals in successfully maintaining an active lifestyle. Thus, this study's primary aim included the development of a valid measure for assessing empowerment in the exercise domain.

\section{Expected Relationships}

The purpose of this study was to examine two important outcome variable measures (i.e., OES and EES) in exercise. The experience of class ownership was hypothesized to be a necessary predecessor for individuals' exercise empowerment development. When participants are given the ownership to try different exercise options in class, new challenges can be attempted in a safe, non-threatening environment. Not all challenges attempted may end as the participants hoped; however, learning from the attempts and being supported to continue trying, may build the participants' sense of exercise empowerment. Through these experiences, individuals may develop the belief that they can positively influence their health through exercise. If this sense of empowerment was developed over the exercise class' duration (e.g., semester), then the participants' chances of successfully continuing their pursuit of health through exercise should increase as their exercise empowerment grows.

The study's hypotheses were based on AGPT tenets (Figure 1). Specifically, the caring climate was hypothesized to positively predict ownership, and to indirectly predict empowerment through ownership. The task-involving climate was hypothesized to positively predict ownership; as well as, positively predict empowerment directly and indirectly through ownership. The ego-involving climate was hypothesized to negatively predict ownership, and to 
negatively predict empowerment through ownership. Lastly, ownership was hypothesized to positively predict empowerment.

\section{METHOD}

\section{Participants}

Students $(N=414 ; M=21.25$ years old; male 37\%, female 63\%) at a Midwestern U.S. university were surveyed. They were participating voluntarily in a variety of semester-long exercise classes, ranging from aerobics to weight training, and individual to team sports. The students represented all classification levels: $13.5 \%$ freshmen, $26.1 \%$ sophomores, $20.3 \%$ juniors, $34 \%$ seniors, and $4.5 \%$ other. The majority of the participants were of Caucasian descent (84.7\%), followed in frequency by African American (3.9\%), Asian (3.1\%), Hispanic (3.1\%), and Mixed (2.7\%), Other (1\%), and Native American (0.5\%).

\section{Procedures}

Approval to conduct this study was received from the University of Kansas Human Subjects Institutional Review Board. The participants were surveyed during their regular class time over the final two weeks of a fall semester to ensure that they had adequate time to develop their perceptions regarding both the class climate components (caring, task-, and ego-involving) and the dependent variables (exercise class ownership and exercise empowerment). Informed assent was received prior to participants completing the survey. All surveys were completed anonymously, and within approximately 20 minutes. To ensure confidentiality during survey administration and completion, the exercise class teachers were not in the room.

\section{Measures}

Demographic Information. The final portion of the survey asked participants to provide grade, age, gender, race/ethnicity, and class information. For each of the following measures, the 
participants responded using a 5 -point scale $(1=$ strongly disagree, $2=$ disagree, $3=$ not sure, $4=$ agree, and $5=$ strongly agree) .

Caring Climate Scale (CCS). The 13-item CCS was used to determine the degree to which participants perceived a caring class climate (Newton, Fry et al., 2007). This measure's full set of items can be found in Newton, Fry et al. (2007). The stem used for each item in this study was "In this physical activity class ..." and a sample item: "... the teacher is kind to the students." Prior researchers' confirmatory factor analysis (CFA) provided reliability and validity evidence for the CCS with youth, including a Cronbach's alpha coefficient value of .92 and correlations, as hypothesized, with the task-involving climate (strongly positive), expectation of future participation (moderately positive), and ego-involving climate (moderately negative; Newton, Fry et al., 2007). More recently, the use of the CCS was found to have a criterion reliability (CR) value of .96 and average variance extracted (AVE) value of .94, which provided internal structure validity evidence for the CCS when used with an adult population (Brown, Fry, \& Little, 2013).

Perceived Motivational Climate in Exercise Questionnaire (PMCEQ). The 27-item PMCEQ was used to assess participants' perceptions of the climate as task- or ego-involving (Brown et al., 2013; Huddleston et al., 2012). All of this measure's items can be found in Huddleston, et al. (2012). There are 14 task-involving and 13 ego-involving items. The stem used for each item was "In this physical activity class ..." and sample items include "... the teacher encourages students to improve on skills they are not good at" (task-involving), and “... the teacher gives most of his/her attention to only a few students (most fit, most popular, etc.)" (ego-involving). Brown, et al. (2013) provided internal structural evidence for the use of these measures with adults, including values of .95 (CR) and .86 (AVE) for the task-involving climate and for the ego-involving climate values of .94 (CR) and .84 (AVE). Additionally, the task- 
involving and ego-involving climate constructs were found to have additional construct validity when used with an adult population, because their regression relationships were in the expected direction and magnitude with enjoyment, effort, and competence (Huddleston et al., 2012).

Ownership in Exercise Scale (OES) and Exercise Empowerment Scale (EES). Based on a literature review and the researchers' experiences as coaches and athletes, a selection of scale items for each measure was developed. Exercise psychologists and exercise class leaders reviewed the items' readability and ability to represent the domain of each construct. Based on their feedback, the items were selected, revised or removed. This was done as an iterative process, until a final set of items for each scale remained. The final version of the OES had five items. The final version of the EES had five items. See Table 2 for all OES and EES items.

\section{Statistical Procedures}

To assess the quality of the two new scales' measurement of their respective latent constructs, a CFA was conducted using Mplus 6.0 (Muthén \& Muthén, 1998-2011; Brown, 2006). To conduct the invariance tests that comprise a CFA, two or more groups need be compared with each other to confirm that the measurement across these groups is not biased (Brown, 2006; Little, Card, Slegers, \& Ledford, 2007). For this study, the groups compared were males and females. This was done, because it is important to assess if there is any bias in item response based upon gender (i.e., males and females responded significantly differently to an item; Brown, 2006). This is examined in a CFA framework by the tenability of gender equivalence constraints placed upon the measurement model. In addition, to test for latent mean differences between males and females appropriately, researchers first need to confirm that no significant differences existed within the measurement (CFA) model (i.e., pass strong invariance; Kline, 2011; Little et al., 2007; Brown, 2006). Once the strong invariance test was passed, then any significant latent group differences could appropriately be interpreted as moderation by 
gender and not response bias. The CFA was conducted utilizing the analysis command type $=$ complex, with classroom as the cluster variable due to the nested nature of the data (e.g., students within classrooms), and the low intra-class correlation of .05 (Muthén \& Muthén, 1998-2011).

The three steps of the CFA assessed the measurement invariance of the constructs' indicators in a stepwise fashion (Little, 2013; Little et al., 2007). The first CFA step, configural invariance, tested the fit of the hypothesized model. How well this configural model represented the relationships existent in the data was based upon the cumulative evidence from the configural model's Chi-square statistic, and fit indices (CFI and RMSEA; McDonald \& Ho, 2002). The Chi-square statistic is a conservative test of model fit, which could be significant despite a model representing the data's relationships well (Kline, 2011; McDonald \& Ho, 2002). Therefore, the CFI $\geq .90$ and RMSEA $\leq .08$ (Brown, 2006; Kline, 2011; McDonald \& Ho, 2002) were also used to evaluate the model's fit. Additionally, modification indices were examined to determine if an update of the hypothesized model would significantly improve the model's fit (Brown, 2006; Kline, 2011).

After the climate constructs' indicator-loadings were assessed by an initial configural model, parcels for each of the three climate scales' items were modeled for all future analyses, such that three parcels loaded onto each climate construct (Little, Cunningham, Shahar, \& Widaman, 2002; Little, Rhemtulla, Gibson, \& Schoemann, in press). These parcels were comprised of that construct's scale items, with no cross-loadings onto the other climate constructs modeled (Little et al., 2002). Parceling was only done with the constructs that have had their measurement model quality supported in previously published articles (Brown et al., 2013; Gano-Overway et al., 2009; Newton et al., 2000; Newton, Fry et al., 2007). Parceling the task-involving and ego-involving items was done by facet to decrease the impact of noncommon variance across facets contaminating the latent construct (Little, 2013; Little et al. 2002; 
Little et al. 2012). The caring constructs' indicators were parceled to have three parcels loading as equally as possible, because no facets are present in the CCS. When facets do not exist to guide parceling, then either the approach of pairing stronger and weaker loading indicators together, or using a random approach has been supported as not significantly impacting the quality of the latent construct (Little, 2013; Little et al., 2012). Parceling was not used for the two new constructs, so that the measurement quality of each indicator could be assessed.

The second CFA step - weak invariance - assessed the equivalence of the indicators' loading patterns across groups. The third CFA step - strong invariance - assessed the equivalence of the indicators' intercept patterns across groups. The tenability of the second and third steps was based upon a CFI change of no more than .01 (Cheung \& Rensvold, 2002; Little, Card et al., 2007). The use of the change in CFI for determining the tenability of the weak and strong invariance constraints has been supported due to the highly conservative nature of the Chi-square statistic (Brown, 2006; Kline, 2011). Passing all three invariance tests would provide supportive evidence for the quality of each constructs' set of indicators and those indicators' measurement irrespective of the respondents' gender.

The concurrent validity hypotheses (i.e., tests of the nomological network) were assessed in latent space, using structural equation modeling (SEM). First, the means, variances, and covariances were tested for homogeneity across gender. If homogeneity of variances across gender was attained, then by definition, the covariances were modeled and tested as correlations (i.e., standardized covariances). However, if homogeneity of variances was not attained, then phantom variables would need to be included to directly model and test the significance of the constructs' correlations, rather than relying on the post-estimation, transformation results available in the standardized output (Little, 2013; Little et al., 2007; Little, Slegers, \& Card, 2006). The inclusion of phantom variables does not affect the model's fit, because the phantom 
construct's variance is fixed at 1.0 and regressed upon its respective first-order latent construct (e.g., variance fixed to 0.0). By definition, then, this regression weight would represent the standard deviation of the first-order construct; and the phantom constructs' relationships would all be standardized (i.e., correlations). Once in the correlation metric (e.g., by homogeneous variances or phantom constructs), the constructs' latent relationships could be tested directly for significance. The correlations' values were tested for equivalence across gender, as well as for being significantly different from zero. Then the theory-directed regression pathways were specified in place of the correlations, and assessed for significance. Significance of each step described above was tested directly by the nested model approach (Brown, 2006; Kline, 2011; Little et al., 2007), which compared the Chi-square statistic's value for the model when the parameter of interest was freely estimated to the Chi-square statistic when that parameter was constrained to be 0 . When the change in Chi-square was significant $\left(\Delta \chi_{1}^{2} \geq 10.828, p \leq .001\right)$, the parameter constraint significantly decreased the model's ability to properly represent the dataset's relationships, and the pathway was kept in the final, pruned model.

\section{RESULTS}

\section{Measurement Invariance}

There was $2.3 \%$ missing data, so the robust FIML (i.e., full-information maximum likelihood) estimator was used for the CFA and SEM analyses (Enders \& Gottschall, 2011). The CFA model included five latent constructs: the three climates, ownership, and empowerment. All of the OES and EES items were loaded onto their respective constructs. The OES and EES items all had factor-loadings in the adequate to strong range (e.g., .58 - .91). Thus, the latent construct accounted for $34 \%-83 \%$ of each indicator's variance (see Table 2). This five-factor configural model's Chi-square value was significant $\left(\chi_{284}^{2}=729.08\right)$. However, the relative fit indices supported the configural model as an adequately fitting model $\left(\mathrm{CFI}=.91 ; \operatorname{RMSEA}_{(284,414)}=.08\right.$, 
$90 \%$ CI [.072 - .088]; Table 3; Kline, 2011). Additionally, there was one significant $\left(\Delta \chi_{2}^{2}=\right.$ $58.89, p<.001 ; \Delta \mathrm{CFI}=.015)$ modification (correlated residual between EES item 2 and item 3) to the measurement model that was present in both gender grouping's modification indices. This shared item-specific residual variance most likely reflected the similarity of the items' wording (i.e., both related to the participants' knowledge development). If this correlated residual appears in future samples, then removal of one of these items or parceling these items together would be appropriate to decrease the potential for incorporating any of this item-specific residual variance into the latent construct of empowerment (Little, 2013; Little, Rhemtulla, Gibson, \& Schoemann, in press). No other modifications were supported across the gender groupings.

To test the loading structure of the constructs' indicators, the loadings were equated across gender to attain measurement weak invariance. The five factor model passed the weak invariance test based upon the relative change in the CFI model fit value $(\Delta \mathrm{CFI}=.002)$. Next, the indicator intercepts were equated across the two groups to test for strong measurement invariance. The model also passed the strong invariance test based upon the change in CFI ( $\Delta \mathrm{CFI}$ $=.009)$. Thus, measurement invariance was achieved.

Given that a CFA was conducted, McDonald's Coefficient omega was calculated as a more appropriate test of scale reliability than Cronbach's alpha for the OES and EES measures (Zinbarg, Revelle, Yovel, \& Li, 2005). This is because McDonald's Coefficient omega calculation takes into account the items' variance attributed to the latent construct in proportion to the total variance of the items. Each scale's McDonald's Coefficient omega value represented good internal consistency $\left(\Omega_{O E S}=.85 ; \Omega_{\mathrm{EES}}=.89\right)$. The measurement invariance and McDonald's Coefficient omega results all provide evidence that individuals' responses to the two new measures' items were consistent across gender.

Evidence for the Scales' Validity 
Having attained measurement invariance, nomological network validity could be properly assessed through SEM latent analyses. First the latent mean, variance, and covariance structures of the model's two groups needed to be assessed for gender moderation effects. Omnibus tests with parameters (e.g., variances) constrained across gender were tested for homogeneity, followed by individual parameter equivalence tests. The ego-involving climate's latent means were the only ones found to be significantly different $\left(\Delta \chi_{5}^{2}=49.75, p<.001\right)$ by gender. Males reported $(M=2.06)$ a significantly higher ego-involving climate than females $(M=1.65)$. All other latent means were not significantly moderated by gender. On average, the participants perceived their activity class climate as low in ego-involving characteristics $\left(M_{\text {male }}=2.06, M_{\text {female }}\right.$ $=1.65)$, and high in caring $\left(M_{\text {male }}=4.65, M_{\text {female }}=4.68\right)$, and task-involving characteristics $\left(M_{\text {male }}=4.01, M_{\text {female }}=4.19\right)$. The participants also, on average, perceived themselves to have a high sense of class ownership $\left(M_{\text {male }}=4.21, M_{\text {female }}=4.09\right)$ and empowerment in exercise $\left(M_{\text {male }}\right.$ $=4.06, M_{\text {female }}=4.26$; see Table 1$)$. The variance homogeneity test was passed by all the constructs, except ego-involving climate. The male's ego-involving climate responses were significantly $\left(\Delta \chi_{1}^{2}=21.11, p=.0008\right)$ more varied $(S D=.74)$ than the females' responses $(S D=$ .45). Therefore, the female participants' perception of the ego-involving climate in the exercise classes was significantly more homogenous than the male participants' perception.

Due to the ego-involving climate's variance heterogeneity, phantom constructs for each first-order latent construct were added to the model, so that the constructs' correlations could be directly tested. The results of directly testing the latent correlations for invariance across gender were all non-significant based upon the Chi-square difference test $\left(\Delta \chi_{10}^{2}=13.91, p=.18\right)$. Therefore, the latent correlations were constrainable across gender. Thus, the only two latent parameters significantly moderated by gender were the mean and variance of the ego-involving climate. 
All of the constructs' correlations were significant $(p<.001$; Table 1$)$. The correlations of the participants' perceptions of the climate with ownership, and empowerment, were consistent with the theoretically-informed a priori directions and magnitudes. First, there was a significant, positive relationship between perceptions of a caring and a task-involving climate $(r=.63)$; while both were significantly, negatively correlated with perceptions of an ego-involving climate $\left(r_{\text {care }}=-.54, r_{\text {task }}=-.42\right)$. Second, ownership and empowerment had similar significant relationship patterns: positive with caring $\left(r_{\mathrm{own}}=.65 ; r_{\mathrm{emp}}=.34\right)$ and task-involving $\left(r_{\mathrm{own}}=.65\right.$; $\left.r_{\mathrm{emp}}=.57\right)$, and negative with ego-involving $\left(r_{\mathrm{own}}=-.48 ; r_{\mathrm{emp}}=-.26\right)$ climate perceptions. Third, the ownership and empowerment correlation $(r=.54)$, revealed a moderately positive, significant relationship representing a $29 \%$ overlap in variance. This supports ownership and empowerment being two related, yet distinct constructs. These results provide validity evidence supporting the ownership and empowerment constructs. Additionally, the greater magnitudes of the climate correlations with ownership provide initial evidence in support of ownership as a more proximal outcome variable than empowerment.

The next step in building validity evidence would be the illustration of predictive relationships. Due to the cross-sectional nature of this study's data, however, only theory-driven regression pathways could be modeled. This study's primary theory-driven hypothesis was that the climates would indirectly predict empowerment through ownership. Given that the homogeneity of the correlations across gender was illustrated, the theory-based indirect path analysis was conducted at the phantom construct level, and the regression beta weights were constrained across gender. Thus, the hypothesized indirect effects of the climates on empowerment through ownership were modeled, in addition to the climates' direct effects on both ownership and empowerment. The climate constructs remained inter-correlated with each other. The following directed pathways were found to be significant: caring to ownership $\left(b^{*}=\right.$ 
$.34, p<.001)$, task-involving to ownership $\left(b^{*}=.37, p<.001\right)$, ego-involving to ownership $\left(b^{*}\right.$ $=-.15, p<.001)$, and task-involving to empowerment $\left(b^{*}=.38, p<.001\right)$. Finally, the theorybased, directed pathway from ownership to empowerment was found to be significant $\left(b^{*}=.29\right.$, $p<.001$; Figure 1). Thus, the alignment of the theory-driven path analysis with the a priori hypothesized relationships provided additional nomological network validity evidence.

\section{DISCUSSION}

The purpose of this study was two-fold. The first purpose was to assess the measurement model for the two new measures, OES and EES. The second purpose was to examine the nomological network validity support for the two new constructs, both with each other and the perceived motivational climates.

\section{Measurement Invariance}

The results provided strong initial support for the reliability and validity of these two new measures. Both measures' McDonald's Coefficient omega values were at or near .90, which indicates excellent internal consistency. Further, the achievement of the strong invariance standard provided evidence for measurement invariance across gender for both constructs' factor structure. The ownership and empowerment findings provide preliminary support that the scales' items measured their respective nomological net area of interest, and that these two measures' constructs are independent of each other.

This study also laid the groundwork for the continued use of the OES and EES by the concurrent theory-driven validity support for the ownership and empowerment constructs. First, all the constructs' correlations were significant in the a priori hypothesized directions. This is an important first step in building validity evidence. The climate constructs' relationships were all in line with prior AGPT research directions and magnitudes (Newton, Fry et al., 2007; Roberts \& Treasure, 2012). Using AGPT, the correlations were then modeled as directed pathways, such 
that the climate constructs were predicting ownership and empowerment, as well as ownership predicting empowerment. The final, pruned version of this model did provide support for the hypothesized climate to ownership pathways. It also supported the climate constructs affecting empowerment indirectly through ownership. Lastly, the direct pathway from task-involving climate to empowerment was also found to be significant. This is the most reasonable climate construct to be a significant direct and indirect predictor of empowerment, because the taskinvolving climate emphasizes individual effort and improvement, and is associated with the instructor providing positive and informative feedback (Magyar et al., 2007; Smith, Fry, Ethington, \& Li, 2005). Overall, these validity findings supported the following: (a) empowerment and ownership as two distinct, but related constructs, (b) the ownership construct was more closely associated with the participants' climate perceptions than the empowerment construct, and (c) participants' perceived exercise empowerment was more closely associated with their perception of ownership than their perception of the task-involving climate alone. These findings support a priori hypothesized relationships, and set the foundation for further research with these quantitative measures.

In addition, this study's invariance testing was able to expand on the measurement modeling technique proposed in earlier research by Newton et al. (2000) for the ego-involving climate construct of the Perceived Motivational Climate in Sport Questionnaire-2 (PMCSQ-2). The current study's analysis design took advantage of a more modern analysis technique (i.e., item parceling) to load the scale's facets onto the first order ego-involving climate construct. This approach blended the two best fitting models from Newton et al.'s (2000) earlier work.

\section{Future Research}

This study provided an initial examination of the reliability and validity of two new exercise psychology measures, and its limitations should be noted. First, although the cross- 
sectional design was useful and efficient to provide preliminary measurement support for these new measures, longitudinal research is needed to confirm the directionality of the theory-driven pathway relationships. Second, the participants were primarily 18-22 year old undergraduate students. Although an important population to study, undergraduates are commonly studied. Third, to determine if the correlated residual between two of the EES' items is sample specific, continued examination of the measurement model for this relationship across other samples is needed to confirm if parceling these items together should be recommended as the preferred internal structure. The latter two points highlight the need for research with other populations to increase the generalizability of the results. Research examining how youth's empowerment toward exercise can be fostered early is important given the current sedentary epidemic. Future research could include longitudinal studies examining the temporal development and relationships of different motivational responses (e.g., effort, ownership, enjoyment, and empowerment), as well as, the longitudinal invariance of OES and EES. Such studies would build additional internal structure and nomological network validity evidence for these new measures.

Previous research has shown the connection between individuals' perceiving a highly caring and task-involving climate and reporting greater interest in continued exercise participation. The two new constructs (e.g., ownership and empowerment) employed in this study may help explain the mechanism behind the previously reported associations of taskinvolving and caring climates with participants' continued physical activity interest. Specifically, the positive and supportive climate appears to promote ownership directly; and through ownership, the climate seems to promote participants' exercise empowerment. The inclusion of ownership and empowerment in future AGPT research will provide further insight into the 
mechanism behind people's successful development and maintenance of lifelong exercise behavior. 


\section{References}

Auweele, Y. V., Rzewnicki, R., \& Van Mele, V. (1997). Reasons for not exercising and exercise intentions:A study of middle-aged sedentary adults. Journal of Sports Sciences, 15, 151165.

Barnekow-Bergkvist, M., Hedberg, G., Janlert, U., \& Jansson, E. (1996). Physical activity pattern in men and women at the ages of 16 and 34 and development of physical activity from adolescence to adulthood. Scandinavian Journal of Medicine \& Science in Sports, $6,359-370$.

Blinde, E. M., Taub, D. E., \& Han, L. (1993). Sport participation and women's personal empowerment: experiences of the college athlete. Journal of Sport \& Social Issues, 17, 159-168.

Brown, T. A. (2006). Confirmatory factor analysis for applied research. New York, Guilford Press.

Brown, T. C., \& Fry, M. D. (2013). Relationship of exercise participants' perceptions of the caring climate to their motivational responses in college aerobic classes. Women and Health, 843-857.

Brown, T. C., Fry, M. D., \& Little, T. D. (2013). The psychometric properties of the perceived motivational climate in exercise questionnaire. Measurement in Physical Education and Exercise Science, 17, 22-39. doi: 10.1080/1091367X.2013.741360

Cheung, G. W., \& Rensvold, R. B. (2002). Evaluating goodness-of-fit indexes for testing measurement invariance. Structural Equation Modeling, 9, 233-255. doi: 10.1207/S15328007SEM0902_5

Chomitz, V. R., Slining, M. M., Mcgowan, R. J., Mitchell, S. E., Dawson, G. F., \& Hacker, K. A. (2009). Is there a relationship between physical fitness and academic achievement? 
Positive results from public school children in the northeastern United States. Journal of School Health, 79, 30-37. doi: 10.1111/j.1746-1561.2008.00371.x

Duda, J. L., Chi, L., Newton, M. L., Walling, M. D., \& Catley, D. (1995). Task and ego orientation and intrinsic motivation in sport. International Journal of Sport Psychology, $26,40-63$.

Duda, J. L., \& Nicholls, J. G. (1992). Dimensions of achievement motivation in schoolwork and sport. Journal of Educational Psychology, 84, 290-299.

Enders, C. K., \& Gottschall, A. C. (2011). Multiple imputation strategies for multiple group structural equation models. Structural Equation Modeling: A Multidisciplinary Journal 18: 35-54. doi: 10.1080/10705511.2011.532695

Enghag, M., Gustafsson, P., \& Jonsson, G. (2009). Talking physics during small-group work with context-rich problems - analysed from an ownership perspective. International Journal of Science and Mathematics Education, 7, 455-472. doi: 10.1007/s10763-0089125-Z

Enghag, M., \& Niedderer, H. (2008). Two dimensions of student ownership of learning during small-group work in physics. International Journal of Science and Mathematics Education, 6, 629-653. doi: 10.1007/s10763-007-9075-x

Gano-Overway, L. A., Guivernau, M., Magyar, T. M., Waldron, J. J., \& Ewing, M. E. (2005). Achievement goal perspectives, perceptions of the motivational climate, and sportspersonship: Individual and team effects. Psychology of Sport and Exercise, 6, 215232.

Gano-Overway, L. A., Newton, M., Magyar, T. M., Fry, M. D., Kim, M.-S., \& Guivernau, M. R. (2009). Influence of caring youth sport contexts on efficacy-related beliefs and social behaviors. Developmental Psychology, 45, 329-340. 
Holwegner, R., \& Weber, T. (2009). Health: M-1 Obesity: Trends, consequences, and emerging strategies Kansas Legislator Briefing Book 2009 (pp. 1-10). Topeka: Kansas Legislative Research Department.

Huddleston, H., Fry, M. D., \& Brown, T. C. (2012). Corporate fitness members' perceptions of the environment and their intrinsic motivation. Revista de Psicología del Deporte, 21, 15 23.

Kline, R. B. (2011). Principles and practice of structural equation modeling (3rd ed.). New York: The Guilford Press.

Lavoi, N. M. (2007). Expanding the interpersonal dimension: Closeness in the coach-athlete relationship. International Journal of Sports Science and Coaching, 2, 497-512. doi: $10.1260 / 174795407783359696$

Little, T. D. (2013) Longitudinal Structural Equation Modeling. New York: Gilford Press.

Little, T. D., Card, N. A., Slegers, D. W., \& Ledford, E. C. (2007). Representing contextual effects in multiple-group MACS models. In T. D. Little, J. A. Bovaird \& N. A. Card (Eds.), Modeling Contextual Effects in Longitudinal Studies (pp. 121-202). Mahwah, NJ: Lawrence Erlbaum.

Little, T. D., Cunningham, W. A., Shahar, G., \& Widaman, K. F. (2002). To parcel or not to parcel: Exploring the question, weighing the merits. Structural Equation Modeling, 9, 151-173. doi: 10.1207/S15328007SEM0902_1

Little, T. D., Rhemtulla, M., Gibson, K., \& Schoemann, A. M. (in press). Why the items versus parcels controversy needn't be one. Psychological Methods.

Little, T. D., Slegers, D. W., \& Card, N. A. (2006). A non-arbitrary method of identifying and scaling latent variables in SEM and MACS models. Structural Equation Modeling: A Multidisciplinary Journal, 13, 59-72. doi: 10.1207/s15328007sem1301_3 
Magyar, M. T., Guivernau, M. R., Gano-Overway, L. A., Newton, M., Kim, M., Watson, D. L., \& Fry, M. D. (2007). The influence of leader efficacy and emotional intelligence on personal caring in physical activity. Journal of Teaching in Physical Education, 26, 310319.

McDonald, R. P., \& Ho, M. H. (2002). Principles and Practice in Reporting Structural Equation Analyses. Psychological Methods, 7, 64-82. doi: 10.1037/1082-989X.7.1.64

Muthén, L. K., \& Muthén, B. O. (1998-2011). Mplus User's Guide (6th ed.). Los Angeles, CA: Muthén \& Muthén.

Newton, M., Duda, J. L., \& Yin, Z. (2000). Examination of the psychometric properties of the Perceived Motivational Climate in Sport Questionnaire-2 in a sample of female athletes. Journal of Sports Sciences, 18, 275-290. doi: 10.1080/026404100365018

Newton, M., Fry, M. D., Watson, D. L., Gano-Overway, L. A., Kim, M. S., Magyar, M. T., \& Guivernau, M. R. (2007). Psychometric properties of the caring climate scale in a physical activity setting. Revista de Psicologia del Deporte, 16, 67-84.

Newton, M., Watson, D. L., Gano-Overway, L. A., Fry, M. D., Kim, M.-S., \& Magyar, M. T. (2007). The role of a caring-based intervention in a physical activity setting. The Urban Review, 39, 281-299. doi: 10.1007/s11256-007-0065-7

Nicholls, J. G. (1989). The competitive ethos and democratic education. Cambridge, MA: Harvard University Press.

Ownership. In Merriam-Webster. (2009). Retrieved August 1, 2009, from http://www.merriamwebster.com/dictionary/owner

Powell, M. G. (2005). Passionate teachers create passionate students. The Delta Kappa Gamma, $71,52-54$. 
Roberts, G. C., \& Treasure, D. C. (2012). Advances in Motivation in Sport and Exercise (3 ${ }^{\text {rd }}$ ed.). Champaign, IL: Human Kinetics.

Sallis, J. F., \& Patrick, K. (1994). Physical activity guidelines for adolescents: Consensus Statement. Pediatric Exercise Science, 6, 302-314.

Seifriz, J. J., Duda, J. L., \& Chi, L. (1992). The relationship of perceived motivational climate to intrinsic motivation and beliefs about succes in basketball. Journal of Sport \& Exercise Psychology, 14, 375-391.

Smith, S. L., Fry, M. D., Ethington, C. A., \& Li, Y. (2005). The effect of female athletes' perceptions of their coaches' behaviors on their perceptions of the motivational climate. Journal of Applied Sport Psychology, 17, 170-177. doi: 10.1080/10413200590932470

Surgeon General. (1999). Adolescents and young adults. In A report of the surgeon general: physical activity and health. Washington, DC: Office of the Surgeon General \& CDC.

Thøgersen-Ntoumani, C., Ntoumanis, N., \& Nikitaras, N. (2008). Typologies of greek inactive older adults based on reasons for abstaining from exercise and conditions for change. Journal of Sports Sciences, 26, 1341-1350.

United States Department of Health and Human Services. (2008). Physical Activity Guidelines Advisory Committee Report, 2008. Washington, DC: DHSS.

Walling, M. D., Duda, J. L., \& Chi, L. (1993). The perceived motivational climate in sport questionnaire: Construct and predictive validity. Journal of Sport \& Exercise Psychology, 15, 172-183.

World Health Organization. (2013). Fact Sheet: Obesity and overweight. Retrieved from http://www.who.int/mediacentre/factsheets/fs311/en/index.html

World Health Organization. (2010). Global recommendations on physical activity for health. Geneva, Switzerland: World Health Organization. 
Zinbarg, R. E., Revelle, W., Yovel, I., \& Li, W. (2005). Cronbach's $\alpha$, Revelle's $\beta$, and McDonald's $\omega$ : Their relations with each other and two alternative conceptualizations of reliability. Psychometrika, 70, 123-133. doi: 10.1007/s11336-003-0974-7 


\section{TABLES AND FIGURES}

Table 1

Latent Correlations, Standard Deviations, and Means from the Phantom Construct Model

\begin{tabular}{|c|c|c|c|c|c|c|}
\hline & Caring & Task & Ego & Ownership & Empowerment & Means \\
\hline Caring & $.41 / .47$ & & & & & 4.67 \\
\hline Task & 0.63 & $.58 / .63$ & & & & 4.16 \\
\hline Ego & -0.54 & -0.42 & $.45 * / .74 *$ & & & $\begin{array}{c}1.65^{*}(\mathrm{~F}) \\
2.06^{*}(\mathrm{M})\end{array}$ \\
\hline Ownership & 0.65 & 0.64 & -0.48 & $.70 / .62$ & & 4.11 \\
\hline Empowerment & 0.34 & 0.57 & -0.26 & 0.54 & $.68 / .78$ & 4.20 \\
\hline McDonald's Omega & .93 & .88 & .92 & .85 & .89 & -- \\
\hline
\end{tabular}

Note. Standard Deviations are on the diagonal. Female (F) values are listed first, Male (M) values second.

$* p<.001$ significant gender difference. 
Table 2

Scale Item or Parcel Standardized Strong Invariance Factor Loadings

Scale Standardized Factor Loading

Caring Climate

Parcel 1 (Items 2, 5, 9, 12, \& 13) 0.872

Parcel 2 (Items 1, 6, 8, \& 11) 0.913

Parcel 3 (Items 3, 4, 7, \& 10) 0.929

Task-Involving Climate

Cooperative Parcel (Items 2, 4, 5, 9, 13, \& 14) 0.764

Effort Parcel (Items 3, 8, 10, \& 11) 0.837

Improvement Parcel (Items 1, 6, 7, \& 12) 0.912

Ego-Involving Climate

Rivalry Parcel (Items 2, 5, 7, 9, \& 11) 0.819

Performance Parcel( Items 3, 6, 8, 10, \& 13) 0.923

Embarrassment Parcel (Items 1, 4, \& 12) 0.550

Ownership In Exercise

In this exercise class, I feel I have the freedom to adjust class

activities to meet my personal goals and/or ability level.

In this exercise class, I feel my input, interests, and/or needs are considered by the instructor.

0.693

I feel my opinion matters to the instructor. $\quad 0.890$

$\begin{array}{ll}\text { The instructor gives me opportunities to modify } & 0.609\end{array}$ movements/intensities.

$\begin{array}{ll}\text { I experience a sense of ownership in exercise class sessions. } & 0.579\end{array}$

\section{Empowerment In Exercise}

My confidence to do this activity on my own has increased. 0.618

My knowledge of this activity has increased.

I now have a better understanding of the activity's basic $\quad 0.909$

My confidence in my ability to perform the movements/skills $\quad 0.802$ has increased.

0.691

My instructor's feedback helped to increase my confidence to perform the movements/skills. 
Table 3

Confirmatory Factor Analysis Invariance Test Results

\begin{tabular}{|c|c|c|c|c|c|c|c|c|c|c|}
\hline Model & $\chi^{2}$ & $\begin{array}{l}\text { Scaling } \\
\text { Factor }\end{array}$ & $\begin{array}{l}\text { Chi-SqTRd } \\
\text { (adjusted) }\end{array}$ & $d f$ & $p$-value & $\begin{array}{l}\text { RMSEA } \\
{[90 \% \mathrm{CI}]}\end{array}$ & CFI & NNFI & $\triangle \mathrm{CFI}$ & PASS \\
\hline Null Model & 4519.125 & 1.217 & 5499.78 & 380 & 0.00 & $\begin{array}{c}0.244 \\
{[.238-.251]}\end{array}$ & 0.000 & 0.082 & - & - \\
\hline Configural Model & 628.053 & 1.139 & 715.35 & 284 & 0.00 & $\begin{array}{c}0.077 \\
{[.069-.085]}\end{array}$ & 0.913 & 0.901 & - & ACCEPT \\
\hline $\begin{array}{l}\text { Configural Model, } \\
\text { Emp3\&4 Correlated }\end{array}$ & 582.041 & 1.141 & 664.11 & 282 & 0.00 & $\begin{array}{c}.072 \\
{[.064-.080]}\end{array}$ & .928 & .913 & +.01 & YES \\
\hline Weak Invariance & 597.004 & 1.141 & 681.18 & 296 & 0.00 & $\begin{array}{c}.070 \\
{[.062-.078]}\end{array}$ & 0.933 & 0.922 & +.005 & YES \\
\hline Strong Invariance & 645.262 & 1.156 & 745.92 & 310 & 0.00 & $\begin{array}{c}.072 \\
{[.065-.080]}\end{array}$ & .920 & .912 & -.01 & YES \\
\hline
\end{tabular}

Note. RMSEA = Root Mean Square Error of Approximation; CFI = Comparative Fit Index; NNFI = Non-Normed Fit Index 


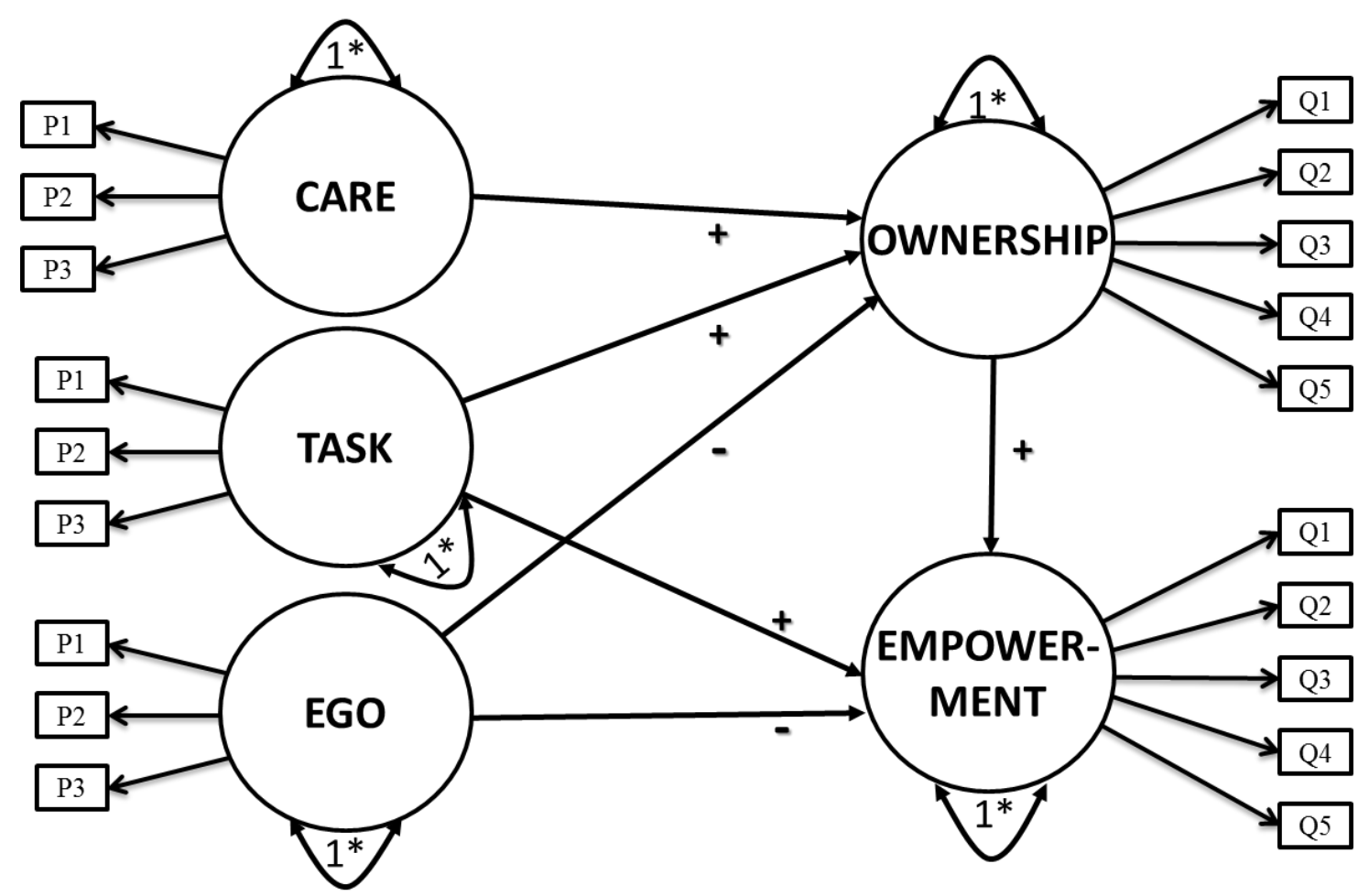

Figure 1. Hypothesized Measurement Model and Directed Latent Pathways.

Note. For readability, this model illustrates only the hypothesized regression pathways, and not the latent correlations between the caring, task-involving, and ego-involving climates that would be estimated as well when this model was analyzed. These latent correlations are, however, illustrated in Figure 2 (final, pruned model). These relationships were hypothesized to be significant for males and females. 


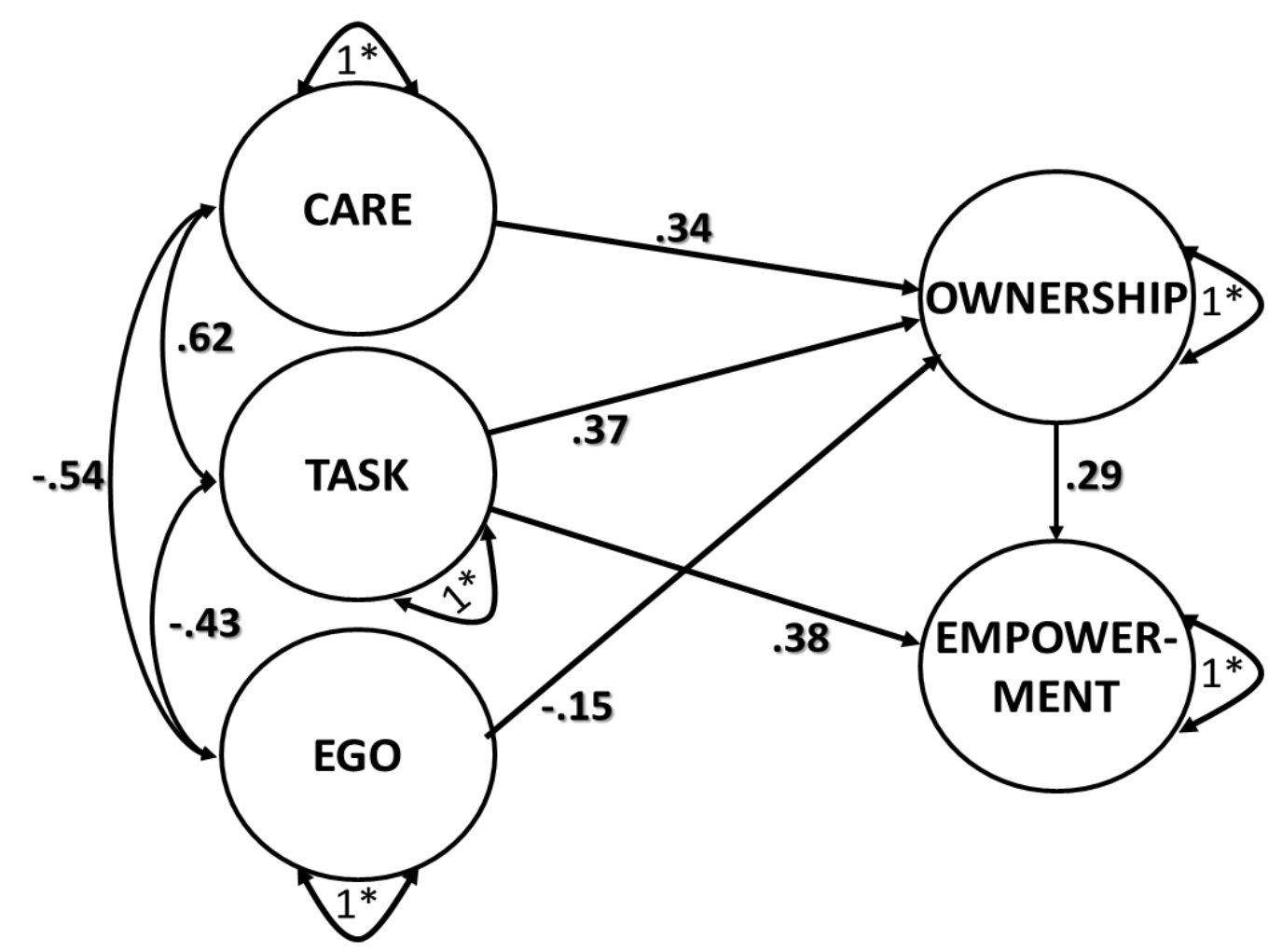

Figure 2. Pruned Phantom Regression Model.

$\chi_{(328, n=414)}^{2}=834.077 ; \mathrm{RMSEA}=.076_{[.069-.084]} ; \mathrm{NNFI}=.90 ; \mathrm{CFI}=.91$ 